\title{
Reform of Diversified Talents Training Mode against the Background of Engineering Education Accreditation
}

\author{
Jun Wang, Mingli Dong, Xiaoping Lou, Bixi Yan \\ School of Instrumentation Science and Opto-Electronics Engineering, Beijing Information Science \& Technology University \\ Beijing, 100192 China
}

\begin{abstract}
The Engineering Education Accreditation is an internationally accepted quality assurance system for engineering education. The OBE concept is fully implemented in the Measurement and Control Technology and Instrument specialty of Beijing Information Science and Technology University, and the talent training system that accords with the accreditation standard of engineering education is established to ensure the training outcomes. On the basis of full coverage of ability reached, the reform of diversified training mode is actively explored. The talents are jointly trained with the domestic and foreign wellknown universities and research institutes. Under the guidance of CDIO, applied engineering talents training with the mode of industry-university-research cooperation is practiced. The remarkable results have been achieved. In 2017, the specialty was approved to be the first-class specialty in Beijing municipal colleges and universities.
\end{abstract}

Keywords-engineering education accreditation; OBE; CDIO; talents training; jointly training

\section{INTRODUCTION}

Engineering education accreditation is the internationally accepted engineering education quality assurance system [1]. The core of accreditation is to make sure that the engineering graduates can meet the established quality standard requirements approved by the industry, and is an eligibility assessment oriented to training objective and graduation export requirements. Washington Accord is the mutual recognition agreement for the undergraduate degree of engineering education, and the tenet is to promote the mutual recognition of engineering degree and the international flow of engineering technical personnel by the multilateral recognition of engineering education qualifications [2]. In June 2016, China became the 18th official member of Washington Accord [3].

Outcome Based Education (OBE) is one of the core concepts of engineering education accreditation [4], and the objective is to ensure the full coverage of students' training objectives. However, the accreditation is not aimed to cultivate students into the same "products", and the full coverage of training objective is only the lowest standard for accreditation. Therefore, "teaching based on ability", "individualized training", and "diversified training" are still important components in specialty construction.
The Measurement and Control Technology and Instruments in Beijing Information Science and Technology University was originated from Precision Measuring Instruments in Beijing Institute of Machinery established in 1958. Since 2008, the specialty has focused on "the applied talent training" characteristic orientation of the school and Chinese engineering education accreditation standard. On the basis of comprehensively implementing OBE concept, ensuring to meet student training objective and capacity, it has actively explored diversified talent training plans good for improving students' capacity, carried out teaching practice, and effectively improved professional talent training quality. The specialty passed engineering education accreditation for two times in 2014 and 2017 respectively, and was selected as the first-batch of first-rated specialties in Beijing municipal universities in 2017.

\section{TALENT TRAINING SySTEM BASED ON OBE CONCEPT}

The specialty should complete top-level design, regard the training objective as the orientation, define the corresponding relationship between internal \& external demands and the training objective, the training objective and graduation requirements, graduation requirements and course system, graduation requirements and teaching contents [5-6]

\section{A. Training Objective}

The core of talent training is the training objective. Since the establishment in 1958 , the specialty has adapted to the national economic development strategies and talent training demand, gradually adjusted its talent training objective, experienced talent training phase oriented to precision measuring instruments, geometric measurement, measurement and control system, mechanical and electronic integration, information detection and processing as well as other industries and fields, and gradually formed its professional characteristics While formulating talent training objective, it is requested to fully coordinate historical accumulations, current demand and long-term demand, and match diversified demands with school-running and talent training and positioning [7]. On this basis, it has built professional education knowledge, capacity and quality structure through the industrial and employer demands, adopted market investigation, employer feedback, alumnus investigation, peer experts consultation and other

[CLC Number] G642.8 [Document Code] A [Article No.]. 
modes, integrated opinions of all parties, formed the training objective of "cultivating engineering technicians that can be engaged in the $R \& D$, manufacturing, technical support, maintenance and operation management of measurement and control instruments, optic-mechanical integration system, information detection and processing equipment in the field of instruments".

\section{B. Talent Training System Design Based on OBE Concept}

The specialty adopts the mode that combines "from top to bottom" and "from bottom to top" (Figure 1), to design the talents training system of measurement and control specialty that can meet OBE concepts.

The mode "from top to bottom" is oriented to the training objective, with concise professional characteristics, and aimed to confirm professional training objective meeting school and specialty positioning; The graduation requirements that can support training objective and cover accreditation standard is set; The capacity support matrix is established, and the support for capacity is implemented in courses, i.e., the teaching objective, capacity cultivation, meeting approach and assessment methods, etc. is defined by course syllabus.

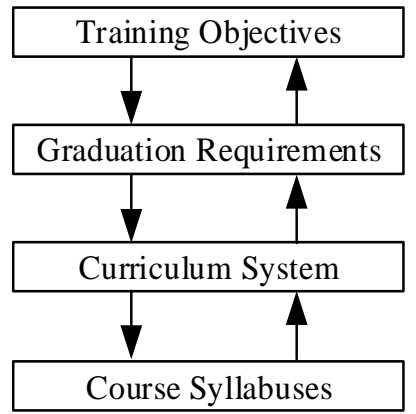

Fig. 1. Flow chart for the talent training system design "from top to bottom" and "from bottom to top"

Confirm the requirements of graduation capacity. Guided by the requirements of graduation capacity, the knowledge, ability and quality structure that students need to master in the process of learning are constructed. Through the requirement of graduation ability, it is clear what students can have when they graduate, and in the form of ability index decomposition, the ability requirement is refined into the index points which are easier to implement in specific teaching links, and the terms that can be evaluated quantitatively or qualitatively are formed [7] .

Construct curriculum system. With graduation requirements and their indicators decomposed into requirements, the curriculum and practice system that can support ability achievement is established, thus forming a mapping matrix between curriculum and ability achievement, which can implement graduation requirements into specific course, that is, each ability indicator point has a clear curriculum to support. While constructing the relationship matrix, we should strengthen the relationship between courses, and take the achievement of one or several graduation requirements as the main line, and the course series (vertical) and the course group (horizontal) are formed. In the course series and the course group, the teaching contents and hours of each course are determined according to the "contribution degree" to the graduation requirements. The overall knowledge structure is more reasonable and complete [7].

Except for theoretical and practical courses, the capacity training beyond knowledge in accreditation standard has been considered during the course setup. The training for students' "non-technical quality" besides the professional knowledge is reinforced through the selection of modular courses of general education such as "economic management", "innovation and entrepreneurship", "cross-cultural communication and exchange", "outstanding engineer quality education" as well as the teaching links such as "introduction to specialty" and "second classroom". Through the practice links of "comprehensive professional practice" and "graduation project", students' ability to solve "complex engineering problems" is trained.

Design the syllabus. Firstly, it is requested to consider the contribution demand of the course for realizing professional capacity training, and then formulate course objectives, and confirm corresponding teaching contents, teaching methods, approaches and individualized teaching strategies, etc. Therefore, it is requested to highlight the following contents in teaching outline: the position and role of the course in the professional curriculum system; the course objectives to meet capacity requirements, and the support to meet graduation requirements; the safeguard measures and ways to achieve course objectives; the evaluation methods of course objectives achievement degree, etc.

On the basis of "from top to bottom" design, it is also requested to adopt the mode of "from bottom to top", starting from the course objectives, sort out the support relationship step by step in the reverse direction to support the training objectives.

After repeated "from top to bottom" and "from bottom to top" design, the scientific, reasonable and qualified training system that can meet accreditation standards has been formed.

\section{DiVERSIFIED TALENT CULTIVATION MODE GOOD FOR IMPROVING STUDENTS' CAPACITY}

Engineering education accreditation emphasizes that students are the center and all students are oriented. On the basis of ensuring the full coverage of training objectives, it is also requested to actively explore diversified talent training modes. The diversified and effective training modes are formed by international joint training, high-level talent crossed training plan, school-enterprise cooperation, etc., and the personalized talent training objective solutions suitable for personal characteristics and capacity are provided to students.

Beijing Municipal Education Commission formulated "high-level talent crossed training plan for universities in Beijing" in 2015 [8], and the key work in the plan includes the "double-training plan" for Beijing municipal universities and Beijing central universities to jointly train students, the "external training plan" for Beijing municipal universities and overseas famous schools to jointly cultivate students, and the "practical training plan" for improving students' practice and 
scientific research innovation capacity. Based on these plans, we have carried out " $3+1$ " mode of "double-training plan" oriented to "high-precision project" and "medical equipment manufacturing" with Tsinghua University and University of Science \& Technology Beijing respectively, "1+2+1" mode "external training plan" with Oakland University, and "practical training plan" with Chinese Academy of Sciences, National Institute of Metrology, China, etc. By combing with " $2+2 "$ and " $2+1+1 "$ and other international jointly training modes with Oakland University as well as the jointly training with famous enterprises, it has enriched and expanded the approaches to meet the training objectives. The domestic and foreign combined, school-institute cooperated, and schoolenterprise cooperated talent training modes have been formed to meet diversified training demands for different types of students.

In addition, a high-level team of teachers based on the Innovative Team of the Ministry of Education and Beijing Excellent Teaching Team has gradually formed, and the virtual teaching and research rooms have been built with Tsinghua University, University of Science \& Technology Beijing, and Beijing Institute of Technology, etc. to improve the educational quality.

\section{APPLIED ENGINEERING TALENT TRAINING UNDER INDUSTRY-UNIVERSITY-RESEARCH COMBINED MODE}

CDIO refers to "Conceive", "Design", "Implement" and "Operate", which can help engineering students study the entire process practice based on the product $\mathrm{R} \& \mathrm{D}$ period, and cultivate system engineering capacity and the professional quality of engineers [9].

By combining with the specific "engineering technical talent" training demand, it regards CDIO concept as the guidance. This can not only be reflected in teaching professional knowledge and principle, but also training talents with the professional quality of engineers as well as the capacity to solve "complicated engineering problems" in engineering design, the capacity to give comprehensive considerations to "non-technical factors" in social, natural, health, laws and systems, etc., And the capacity of teamwork and self-learning, etc.

Under the CDIO mode, we study and explore the implementation of $\mathrm{CDIO}$ in scientific research projects, scientific and technological activities, subject competitions, series of curriculum practice, professional comprehensive practice and graduation design, so that students can participate in the design and practice of a relatively complete measurement and control system, and improve their engineering practice ability.

We provide the conditions and environment similar to actual engineering for students, and build engineering practice and innovation platform by extracting and converting teachers' scientific research projects and the cooperation projects of the enterprise into the design-oriented experimental projects, the comprehensive practice topics, graduation design, scientific innovation topics, etc. With this mode we can give students the opportunity to directly participate in the scientific research, understand the research methods, and experience the working process. Most importantly, it is to help students feel the success and joy to solve actual problems by using the learned knowledge based on personal endeavors. According to statistics, in the last four years, above $90 \%$ graduation designs belong to the category of engineering design, and above $70 \%$ directly related to the scientific research projects.

\section{REFORM EFFICIENCY}

The reform and practice of diversified talent training modes based on OBE concept has been strongly supported by Beijing and Beijing Information Science and Technology University, and a comprehensive reform and practical exploration has been carried out, which has achieved remarkable results.

(1) In 2017, the specialty was approved to be the first-class specialty in Beijing municipal colleges and universities, which is the recognition of the reform and development of specialty construction.

(2) The talent training system has been recognized by Chinese Engineering Education Accreditation Association, and passed the accreditation in 2015 and 2018 respectively.

(3) The teaching team was awarded as the Beijing Excellent Teaching Team, and the Innovative Team of the Ministry of Education. Both the approaches and experience of team construction, specialty construction, course building, etc. have a demonstration role in Colleges and universities.

(4) Undergraduates of the specialty have outstanding scientific and technical capacity, extraordinary performances, and can meet the positioning of engineering talent training. Above $90 \%$ students used to participate in scientific and technical innovation projects or won awards in college. Over the past four years, students of the specialty declared 99 scientific and technical innovation projects, including about $1 / 5$ national-level projects. The number of participants is 1.2 times that of professional students.

(5) Multi-approach and multi-mode collaborative training has gradually formed a certain scale. Over the past four years, $43.8 \%$ students of the specialty participated in high-level talent training plans, which have improved students' capacity obviously and expanded their horizons.

(6) The employment rate of graduates is high, and the feedback results are excellent. The employers have a good overall evaluation of the graduates, especially in the aspects of engineers' accomplishment, professional ethics, ability to analyze and solve practical problems, cooperative communication ability and job adaptability.

\section{CONCLUSION}

In recent years, we have explored a reform road for diversified talent training modes that can meet the concept of engineering education accreditation, and achieved remarkable results. Taking this as an opportunity, we will improve its level and influence in an all-round way, create a new cross-brand specialty with first-class characteristics in China, and provide experience and reference for the reform of engineering education and the construction of international first-class specialty. 


\section{ACKNOWLEDGMENT}

This article is the research achievement of key teaching reform projects of Beijing Information Science and Technology University (2016JGZD01, 2012JGZD02).

About the Author:

Jun WANG, Director for the School of Measurement and Control Technologies and Instrument, Beijing Information Science and Technology University, Associate Professor and Doctor;

Mingli DONG, Dean for the School of Instrument Science and Opto-electronics Engineering, Beijing Information Science and Technology University, the Principal for Measurement and Control Technologies and Instrument Specialty, Professor and Doctor;

Xiaoping LOU, Deputy Dean for the School of Instrument Science and Opto-electronics Engineering, Beijing Information Science and Technology University, Professor and Master;

Bixi YAN, Associate Professor and Master. (Beijing/100192)

\section{REFERENCES}

[1] Patil A, Codner G. Accreditation of engineering education: review, observations and proposal for global accreditation $\mathrm{n}[\mathrm{J}]$. European Journal of Engineering Education, 2007, 32(6):639-651.

[2] Suolan LIU, and Lizhi KONG. Research about the Influence of Engineering Education Accreditation on Information Course Teaching Reform[J]. China Modern Educational Equipment, 2016(19): 43-44.

[3] Ertian HUA, Weirong JI, and Xiangming WU. Exploration and Practice for Engineering Innovation Talent Training under the Background of China joining Washington Accord [J]. China Higher Education Research 2017(1): 82-85.

[4] Zhiyi LI, Hong ZHU, Zhijun LIU and Yuanjing XIA. Higher Engineering Education and Teaching Reform Guided by Achievementoriented Education Concept[J]. Research on Higher Education of Engineering, 2014(2): 29-34.

[5] Zhiyi LI. Demand Docking, Accurate Positioning and Creating Characteristic Underground Education with All Strength [J]. Chinese University Teaching, 2016(7): 22-25.

[6] Ge SONG. Assessment of Learning Achievements under OBE Education Mode[J]. China Modern Educational Equipment, 2018(09): 56-58.

[7] Zhiyi LI. Analysis on Achievement-oriented Concept for Engineering Education Accreditation [J]. China Higher Education, 2014(17): 7-10.

[8] Jun WANG, Mingli DONG, Xiaoping LOU and Bixi YAN. Research on the Training Mode of Collaborative Innovation Capacity Based on Virtual Teaching and Research Platform [J]. Education and Teaching Forum, 2017(13): 161-162.

[9] Zhitang WANG. Research on Training the Practical Innovation Capacity of Students in Local Universities Based on CDIO Concept [J]. Laboratory Research and Exploration, 2017, 36(7): 220-224. 